\author{
Claudia L. Zuñiga-CaÑon \\ JuAN C. Burguillo
}

\title{
URBANCONTEXT: A MANAGEMENT MODEL FOR PERVASIVE ENVIRONMENTS IN USER-ORIENTED URBAN COMPUTING
}

\footnotetext{
Abstract

Nowadays, urban computing has gained a lot of interest in regards to guiding the evolution of cities into intelligent environments. These environments can be appropriated for interactions between individuals that may ultimately affect and modify their behavior. These changes require new approaches that allow us to better understand how urban computing systems should be modeled.

In this work, we present UrbanContext - a new model for designing urban computing platforms that applies the theory of roles to manage the individual's context in urban environments. The theory of roles helps us understand the individual's behavior within a social environment, allowing us to model urban computing systems capable of adapting to an individual's states and needs.

In order to optimize social interaction and offer secure services, UrbanContext collects data in urban atmospheres and classifies behavior according to the individual's change of roles. Likewise, UrbanContext serves as a generic model to provide interoperability as well as facilitate design, implementation, and expansion of urban computing systems.
}

Keywords 


\section{Introduction}

In recent years, research has begun in the scientific community to design and develop urban pervasive systems that can generate social interactions among citizens of a large city; this trend has been labeled Urban Computing. This computing is carried out in a new "third space" between home and work [1]. This "third space" is complex, because it must include interpretations of physical mobility and social context. The intersection generated between mobile computing and social computing (specifying urban interaction spaces) is defined as "urban atmosphere" [2].

Under this precept, we can observe how the behavior of individuals in a society has been affected due to the increment of interconnected systems developed to provide them with information at any time or any place. This requires the search of individualcentered theories that can be applied in urban computing to interpret the dynamic of these behaviors.

The theory of roles proposed by Erving Goffman [3] states that individuals play roles depending on the situations in which they find themselves. Goffman relates the individual to an actor in a play; this approach is relevant to all mobile, urban, and multi-user computing systems.

Kostakos [4] states that the wide variety of activities taking place in cities, along with the inherent difficulty of developing systems in real world environments, make it extremely difficult to approach the design of generalized systems from a purely theoretical basis. It is further known that much of the information generated does not necessarily flow through interconnected devices and transmission media, but rather through people who have devices that, in turn, are associated with other devices. This makes it more difficult to obtain data on dispersed systems.

To address these difficulties, we must combine a systemic view that includes city, people, and technologies under a strong empirical focus. Making sense of collected data and building models of human behavior can help provide information for understanding and designing these new pervasive systems.

The platforms developed for these environments should be designed using schemes that permit us to model individual behaviors in the scenarios mentioned above. In this way, we can offer applications and services that are adapted to the necessities of individuals within the urban context.

Hence, our contribution is the UrbanContext model, oriented towards urban computing, that implements the role approach theory of Ervin Goffman [3] as a method of managing the context of the individual. This offers the advantage of recognizing the state of the individual at a certain moment while offering services without invading his/her privacy. Additionally, this can help generate interactions and establish positive relationships within the social context.

The rest of the paper is organized as follows: In the first section, the fundamental principles identified for the design of the model are introduced. The next section presents previous experiences in urban computing systems; then, the proposal of the implemented model is described, characterizing each of the different components that 
have been defined as well as showing the vision of the model from the point of view of the user, considering his/her roles and contexts. Finally, conclusions and possible future work are presented.

\section{State of the art}

Building ubiquitous systems in urban environments has become a major boom in current and future trends, giving way to the so-called ubiquitous cities. Cities can be considered contextual spaces, where telecommunication systems are coupled at the confluence of millions of people who cross them daily, and that used space becomes a flow of information.

Among scientific literature, we can find different authors who have addressed and contributed to this topic. Their opinions include:

- It is important, according to Chin, Stephan, Gracio, Kuchar, Whitney, and Schuchardt [5], to consider public spaces as potential sites for computing development.

- The Cities, according to Williams and Dourish [6], are complex ecosystems, and this complexity converts them in interesting places for understanding how pervasive computing technology can be used and carried out in everyday life.

- According to Foth [7], software development must be able to support a significant amount of interaction between immediate users as well as encourage casual encounters through social networks.

- According to Kjeldskov and Paay [8], adding a digital layer to the existent social and physical layers could facilitate new ways of interaction that would remodel urban life. Whereas, commercial information providers would create, possess, and maintain a new layer which the public could help in terms of form and content.

In order to consider the model design, we start by defining a city as a space of interaction where the person can experiment different changes of roles involving changes in their behavior. In these spaces of interaction, the community develops a collective consciousness linked to different contexts that are present in the urban atmosphere.

Therefore, our proposal of UrbanContext is a model that allows standardized creation and deployment in real environments of urban computing systems, allowing free development of business models for each specific application from the user's perspective as well as his behavior.

Approaching the modeling of the QoS in a given context, Bernardos speaks [9] about the personal, social, and environmental contexts. Kostakos, et al., in their study about information spheres [10], says that information could be classified in the same aspects.

In our urban atmosphere, we include this classification and information context; but, we also consider that a person may develop different types of roles associated 
with the different context in which he/she operates. This leads to a dynamic change in an individual's behavior in the urban atmosphere.

This perspective of the person, depending on his role under the urban atmosphere, generates a exponential flow of information. This becomes even more complex when it is considered in the perspective mentioned by Suchman [11], where she expresses directly that people improvise patterns, thus creating difficulties when attempting to analyze behaviors as well as modeling them.

It is now important to define the context and application of the role. In the next section, we will discuss the role of the context within urban environments as well as the diverse role changes that an individual can assume inside an urban atmosphere.

\subsection{Context-Aware Computing in an Urban Setting}

Working with urban computing systems is more complex than with ubiquitous systems (even in controlled environment) due to the huge number of variables that play in these kinds of atmospheres.

These environments have a dynamic and unpredictable behavior, which requires us to come up with new ways of thinking about the context that do not exactly fit the traditional categories of experimental design [12]. Dey [13] mentions that there are three main characteristics that an application sensitive to context must support:

- Presentation of information and services to a user.

- Automatic Execution of a user service.

- Labeling of context information to support later recovery.

One of the main challenges is to make context-aware systems which offer appropriate and just-in-time services when the user requires them. But, increasing the customization in a contextual scenario would involve an array of different contextual meanings for each user [12]. Another important aspect mentioned by Dey [13] is to model the context by including the abstraction of the situation, which will be a state description of the relevant entities. Dourish [14] deepens this concept, stating that it is necessary to involve social themes to truly understand the context.

Returning now to the "context" in urban computing, it is important to mention that urban computing systems require the combination of great static knowledge of the city (i.e. urban, social, and cultural information), an even-greater set of dynamic data (originated in real time from heterogeneous data sources), and finally, reasoning about knowledge obtained in real time [15].

Models such as SOCAM[16], JCAF[17], and CAMidO[18] are focused on context management, but this lacks the provision of services and proper community administration. Some architectures like UCAM [19] aim to improve deficiencies in the models, integrating social intelligence as a way to manage the multiple user behaviors. However, these new architectures do not approach the construction of urban computing from the perspective of the individual; whereas, the roles they play within the urban atmosphere determine their behavior. 


\subsection{The use of roles in different scenarios}

In the urban context, we can mention different scenarios where individuals play their roles. These scenarios are influenced by dissimilar variables associated with the state of the individual as well as the state of the environment.

Consider an imaginary person named Miki during a timeline, associated with her urban atmosphere and handling different roles. Miki assumes a role when speaking with her children, a different role when speaking with her friends, and an entirely different role when talking about a business project. This example shows that a user has different and specific needs depending on his/her role and context.

Therefore, the type of behavior is conditioned by the individual's personal context, where fears, feelings, senses, and others issues converge (see Fig. 1). If the individual is sad, his/her behavior in the social context is not the same as if he/she is happy. Then, the analysis of individual behaviors in the urban social context requires various multidisciplinary studies, considering also those related to cognition.

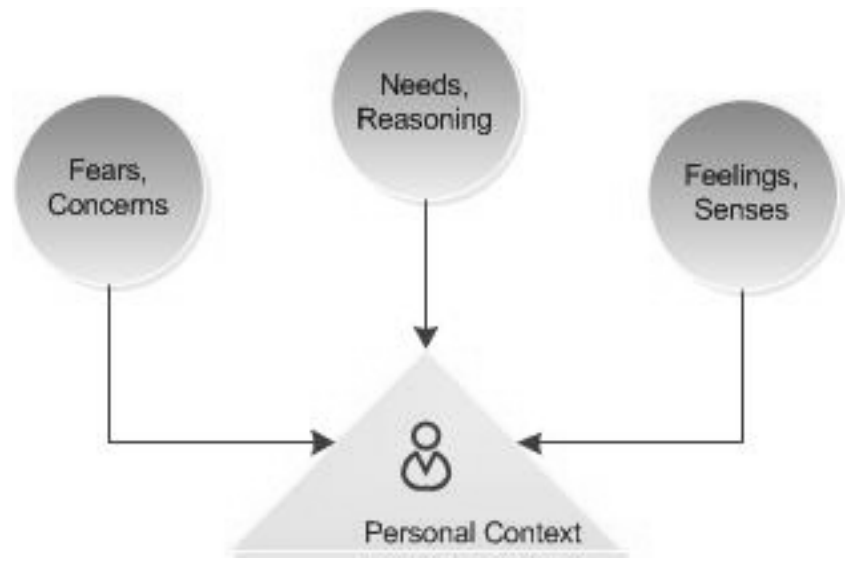

Figure 1. Individual's Personal Context.

In another example, we put Miki in a city center. Miki has arrived there and needs some items, but she does not know anyone in the environment as she is traveling alone. Therefore, it is difficult for her to get help, despite the fact that many people who have what she needs are nearby and willing to help. We should be able to model the context for individuals to express their needs, and that is the environment that offers options to satisfy those needs.

Nowadays, there is a lot of information on the network that allows people to build routes, find groups, search for restaurants, listen to music, read forums, and pay for tickets. This is a cyclical process, experienced again and again by any user. But how do we model the individual's interaction with a system that allows him/her to use services in the urban atmosphere while protecting his/her autonomy and privacy? 
In the next section we describe previous experiences, that we have obtained developing urban systems, where the role of the individual is identified as well as the foundation requirements to model these systems.

\section{Description of our previous experiences}

In this section, we present three projects: Urb@na - Openzoo (developed within a controlled urban context), Urb@naLab (that involved the concept of Living Labs inside urban computing systems), and Guacarí Living Lab (displayed on an open urban environment, in the city of Guacarí, South America). Table 1 summarizes these projects.

Table 1

Projects development.

\begin{tabular}{|c|c|c|}
\hline Project & Urban Environment & Model Characteristics \\
\hline $\begin{array}{l}\text { Urb@na - Openzoo [20], } \\
\text { project co-funded by Admin- } \\
\text { istrative Department of Sci- } \\
\text { ence, Technology and Innova- } \\
\text { tion COLCIENCIAS in Colom- } \\
\text { bia. }\end{array}$ & $\begin{array}{l}\text { Urban computing system de- } \\
\text { veloped in a controlled environ- } \\
\text { ment, tested on site at the zoo } \\
\text { in the city of Cali. }\end{array}$ & $\begin{array}{l}\text { This project was implemented } \\
\text { under a triad approach: } \\
\text { People, Technology and Spaces, } \\
\text { and used the PSP Framework } \\
{[22] \text { defined by Kostakos. }}\end{array}$ \\
\hline $\begin{array}{l}\text { Urb@naLab [23], an Urban } \\
\text { Computing Platform to Offer } \\
\text { Citizen Oriented Services in } \\
\text { Urban Wireless Environments } \\
\text { that Contributes to Living } \\
\text { Labs approach in the Colom- } \\
\text { bian Cities. Project co-funded } \\
\text { by Department of Administra- } \\
\text { tive Science, Technology and } \\
\text { Innovation COLCIENCIAS in } \\
\text { Colombia. }\end{array}$ & $\begin{array}{l}\text { This project linked the Living } \\
\text { Labs to the urban computing } \\
\text { concept. } \\
\text { Urb@naLab conceives the } \\
\text { learning of individuals' likes } \\
\text { and characteristics which can } \\
\text { be obtained from external } \\
\text { sources and/or directly from } \\
\text { the urban computing platform. }\end{array}$ & $\begin{array}{l}\text { Urb@naLab defined four com- } \\
\text { ponents for its architecture } \\
{[24] \text { : co-creation (creation of }} \\
\text { ideas, collaboration, validation } \\
\text { and refining) labeling, interface } \\
\text { and context. }\end{array}$ \\
\hline $\begin{array}{l}\text { Guacarí LivingLab }[25] \text {, } \\
\text { Wireless Networks and Digital } \\
\text { Inclusion Services in the city } \\
\text { of Guacarí, sponsored by the } \\
\text { IDB (Interamerican Develop- } \\
\text { ment Bank) and the Italian } \\
\text { Trust Fund of Information and } \\
\text { Communication Technology } \\
\text { for Development. }\end{array}$ & $\begin{array}{l}\text { This project was displayed at } \\
\text { Guacarí city, a small municipal- } \\
\text { ity of } 32,554 \text { inhabitants }[26] \text {, } \\
\text { located in the western region of } \\
\text { Colombia, South America. }\end{array}$ & $\begin{array}{l}\text { Guacarí LivingLab, adapted } \\
\text { Urb@naLab to develop a plat- } \\
\text { form of services aimed to the } \\
\text { citizens, which allowed creat- } \\
\text { ing technological interactions } \\
\text { among the residents of a big } \\
\text { metropolis, a real open environ- } \\
\text { ment developing a lab in real } \\
\text { time. }\end{array}$ \\
\hline
\end{tabular}

The research involving these three projects was incremental and allowed for the identification of several hints along their development. The first project, 'Urb@na - Openzoo', was developed at the Cali Zoo (a zoo park in South America). In this project, sociologists and anthropologists were asked to study the behavior of individuals within a controlled atmosphere. First, a sample of 400 individuals ( $49 \%$ men and 
$51 \%$ women) was selected. The sample was used to measure the perception of the individuals in the urban atmosphere, as well as the usage and availability of technological resources.

Second, seven work sessions with focal groups composed of 45 individuals were set. As a result, it was observed that an individual establishes different trust levels within his/her social environment, and this reflects on their behavior. One of the main conclusions was the need for clearly-defined characterizations of the individual and the urban atmosphere, when modeling urban computing systems.

The second project developed was Urb@naLab, an urban computing platform to offer services to the citizens, that uses the living-labs methodology in the process of the co-creation of services. The main challenges when developing this platform were: 1) the interaction with the user; 2) a solution for the massive use of data; and 3) a definition and accurate classification of information in order to interpret and provide the appropriate services. In addition, we identified the need for middleware to help understand the interactions of individuala in such an urban context.

The third experiment moved Urb@naLab to a real scenario in an open, noncontrolled environment. This third project was called Guacarí LivingLab, and our objective was to adapt the Urb@naLab platform to a large-scale real environment that allowed measurement of the interactions between individuals as well as their active participation in the different urban atmospheres. In this project, three sessions took place with focus groups. The groups contained 40 individuals, with people of different ages and from sectors like community, government, academia, international organizations, and production areas. The platform was tested with these groups, and the whole process was evaluated.

As a result of this work, we were able to identify that the individual actively participates in the process of service co-creation, from its conception through its final deployment. We also realized that users need motivation to participate, and this could be achieved if the platform possesses the capacity to characterize, identify, and adapt to all of the requirements of each individual.

This information allowed us to identify a series of patterns that contributed to the proposal of urban computing platform modeling. The next section will present these patterns as well as their conception under a model by components using an individual-centered approach.

\section{Urbancontext model based in our previous experiences}

In this section, we describe the implementation of the model, together with the different components that have been defined.

\subsection{UrbanContext Model definition}

We present a series of patterns that were identified to construct an urban computing system (see Fig. 2): 
- Individual, central axis for the urban computing model.

- Interface, the entrance to the system, capable of offering interaction in the clearest possible way.

- Context, plans of the atmospheres where the individual inhabits.

- Urban Atmosphere, identification and characterization of the urban environment.

- Semantic, indexing of information flow in the urban atmosphere.

- Cloud, global storage, the searching for interoperability.

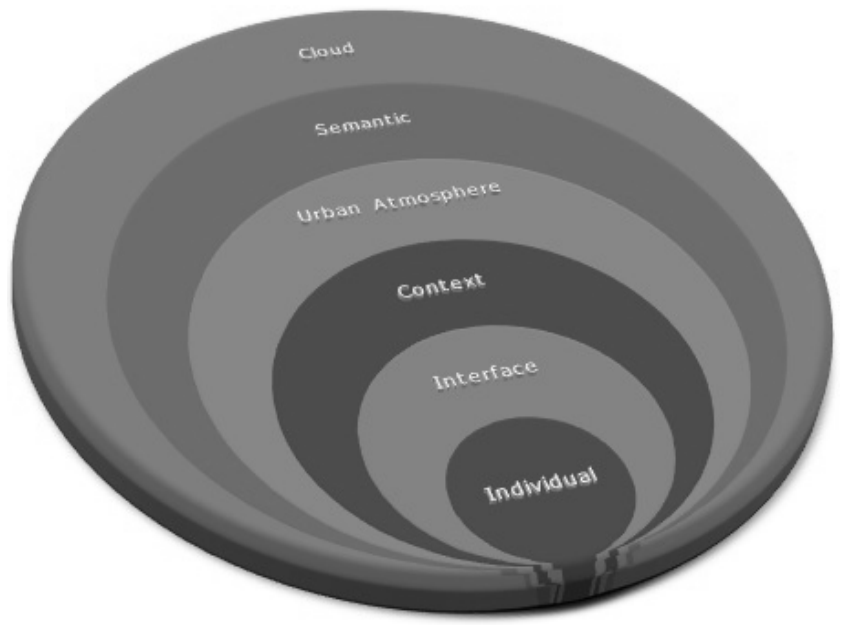

Figure 2. Foundation layers in Urban Computing Systems.

Based on these patterns, UrbanContext proposes several components for urban computing system modeling: roles (urban agent, urban atmosphere, context, and context management), semantics, information management (cloud), services, and interface. The structuring of the model components and their interaction flow can be observed in Figure 3.

UrbanContext is our proposal to provide a model for designing urban systems in pervasive environments. It considers the use of several components to model a large number of variables in the environment and make sense of the collected data to provide systems that are completely ubiquitous. The following is a specification of requirements defined for the components of each model:

Roles Component. It is the most important component of the model and is composed of the following 4 sub-components:

- Urban Agent SubComponent. This sub-component is focused on the characterization of the user. It should collect all user information directly from his interaction, as well as from different social sources to which he is related.

This sub-component enables identification of the individual through a collection of basic information that tends to remain constant, such as name, surname, date 
of birth, and nationality. Also, the sub-component must acquire dynamic data associated with the profile regarding preferences and tastes in order to generate an individual's knowledge base.

- Urban Atmosphere SubComponent. This sub-component allows filtering throughout all data regarding the place, the environment, and the people within the space.

- Context SubComponent. This sub-component is associated with the identification of contexts in which the individual participates in the urban atmosphere, considering that the individual can be in three different contexts: personal, social, and global. Besides, this sub-component collects and identifies the roles of the individuals within each selected context.

Here, we must collect data from external sources (such as sensors and social networks) to identify the behaviors of the individual in such a context.

- Context Management SubComponent. This sub-component focuses on the semantic processing of all the data collected by the other components. It also achieves discovery services, establishes logic of individual behaviors in the atmosphere, builds effective relationships, and eventually provides a recommendation system. Finally, this sub-component provides a significant value to privacy, offering customization without forgetting about privacy threats.
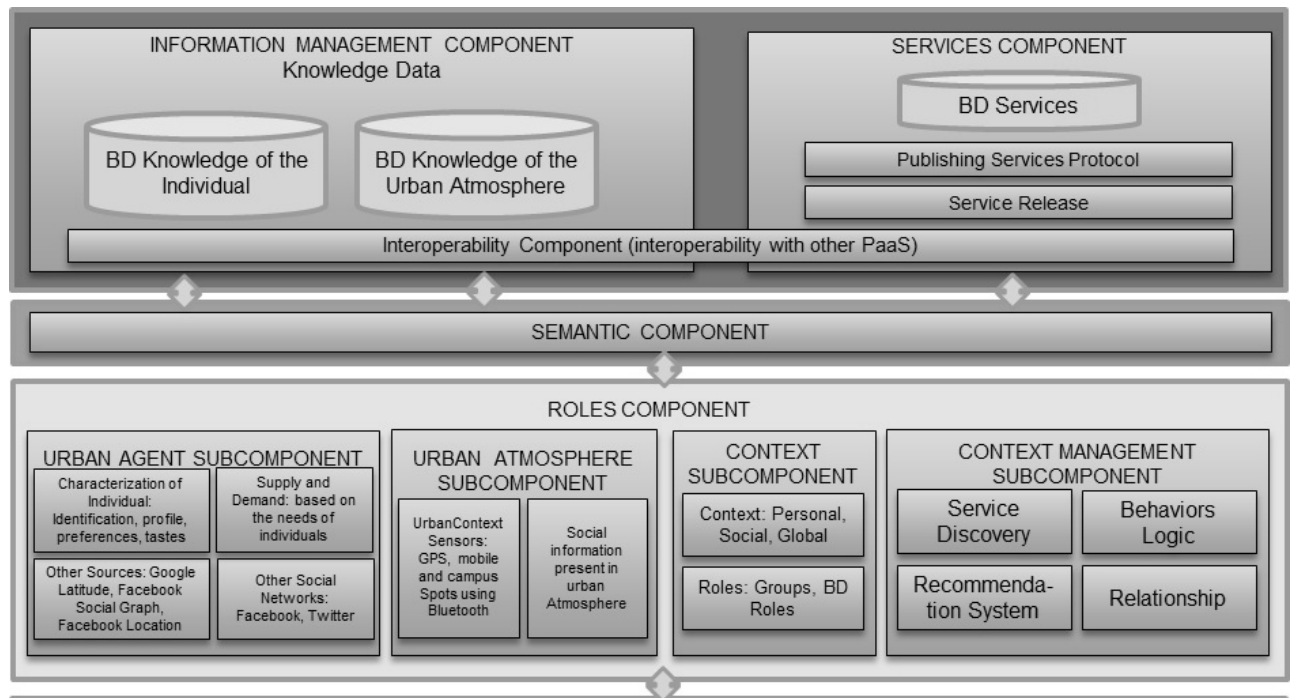

INTERFACE COMPONENT

Figure 3. UrbanContext Model. 
Semantic Component. This component classifies all information obtained from the individual through the appropriate metrics in order to store it in the Information Management Component.

Information Management Component. This component must guarantee the accessibility of data based on standardization, and it must also offer some basic rules for publishing services and define the metrics for data classification.

Information Management can be handled as a PaaS (Platform as a service), including an integration of sub components to provide interoperability between different PaaS's in the future. The Information Management Component will have all of the information provided by the Urban Agent, the Urban Atmosphere, as well as services offered by the Service Component.

This component will serve as an instrument to facilitate data storage in order to process and deliver it to the end user. This component provides interoperability and availability of services.

Services Component. This component allows the publication of service providers by means of a publishing protocol. In addition, these services must be semantically tagged for further processing.

Interface Component. This component offers mechanisms that allow the visualization of information delivered by the Context Management Sub-Component. Therefore, this component must consider friendly interfaces for the pervasive urban atmosphere, for instance, augmented reality.

\subsection{The management of the Context in UrbanContext}

In UrbanContext, management of the context and the roles assumed by the individual are modeled through the Roles Component. This component covers the four designated sub-components: urban agent, urban atmosphere, context, and context management.

An individual can perform different roles that condition his behavior inside the context in which he develops (see Fig. 4).

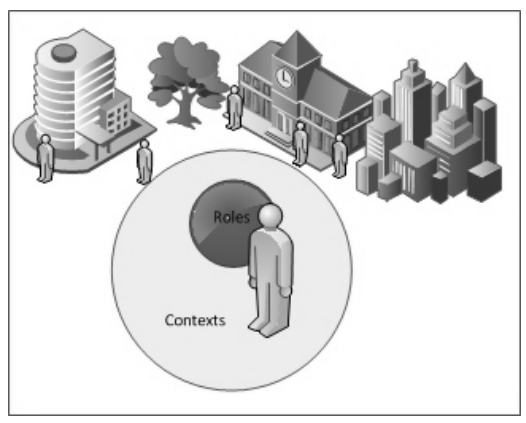

Figure 4. Roles and Context in the Atmosphere. 
This context present in urban atmospheres is not universal and must be classified according to the level of proximity to the individual. In UrbanContext Model, we have identified the participation of the individual in three different contexts: a Personal Context, a Social Context and a Global Context (see Fig. 5).

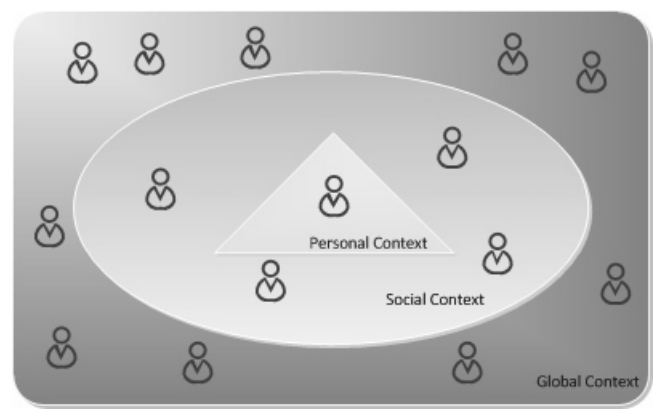

Figure 5. Contexts in Urban Atmosphere.

In the Personal Context, the individual has his own space where he experiments with different needs according to his concerns, fears, feelings, and preferences.

Social Context is focused on the interaction of the individual with other people within the atmosphere. This interaction depends on the role that each individual plays in that situation.

Global Context involves all of the environments that the individual has access to within an urban atmosphere.

Applying Goffman's theory under the approach of the individual's role, it can be established that the individual determines behaviors based on the role that he plays and the context in which he operates. Within every context, one normal cycle exists where the individual generates constant requests, and these are attended through the service deliveries for him/her (see Fig. 6).

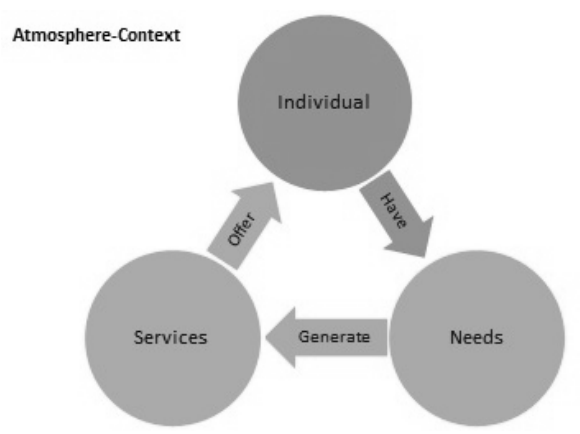

Figure 6. Cycle within Contexts of Atmosphere. 
This context classification combined with role cataloging allows the system to filter information depending on the context and the basis of the individual's needs.

Therefore, individuals can remain connected in the personal context while being disconnected in the social and public contexts. In this way, the system would offer the information they need according to the roles they play at any moment.

\section{Conclusions and future work}

In this paper, we have demonstrated that changes in an individual's behavior are key to modeling urban computing systems. We have also established that introducing a theory about human behavior, like the "theory of roles" in urban contexts, helped us to understand the social behavior of the individual, which is conditioned by the role that he/she wants to play in a specific scenario.

According to the theory of roles, we defined that an urban atmosphere is like the scenery of a play, where the individual represents an actor in the play and assumes a role that determines his behavior according to the situation. Consequently, the services offered by the context must be adapted to these roles, and in this way, offer a level of privacy inside the urban environment.

Based on previous reflections, the UrbanContext computing model was developed using the Erving Goffman's "theory of roles" approach. We consider that this model covers some relevant needs of current urban environments, offering the capacity to identify the individual's needs as well as the management of the individual's roles. This helps to provide an adequate level of privacy within the urban atmosphere.

The main contributions of this model are:

- It provides a model for the design of urban computing platforms using data from experiences obtained in our previously-developed projects.

- The model integrates the theory of roles to manage the context in order to classify the individual's behaviors.

- It facilitates the interaction and establishment of positive relationships within the social environment.

- The model supports the individual's privacy.

- It offers adaptability and interoperability in the development of services for urban environments.

As future work, we consider that the context management models should also measure the interaction level of the individual. To this end, the Guacarí LivingLab will be used to measure the impact of roles in urban environments, in order to get feedback to improve our knowledge as model designers.

\section{Acknowledgements}

This work has been partially supported by the Xunta de Galicia under INCITE Project Number 10 PXIB 322 039 PR. 


\section{References}

[1] Oldenburg R.: Celebrating the Third Place: Inspiring Stories About the "Great Good Places" at the Heart of Our Communities. Marlowe \& Company, New York, 2002.

[2] Paulos E., Jenkins T.: Urban Probes: Encountering our Emerging Urban Atmospheres. CHI 2005, ACM Press, April 2005.

[3] Goffman E.: The Presentation of Self in Everyday Life. Doubleday \& Company Inc., New York - United State, 1959.

[4] Kostakos V., O’Neill E., Penn A., Roussos G., Papadongonas D.: Brief Encounters: Sensing, Modeling and Visualizing Urban Mobility and Copresence Networks. ACM, 2008.

[5] Chin G., Stephan E., Gracio D., Kuchar O., Whitney P., Schuchardt K.: Developing Concept-Based User Interfaces for Scientific Computing. IEEE Computer, September, 2006.

[6] Williams A., Dourish P.: Imagining the City: The Cultural Dimensions of Urban Computing. IEEE Computer, IEEE Press, September 2006.

[7] Foth M.: Facilitating Social Networking in Inner-City Neighborhoods. IEEE Computer, September, 2006.

[8] Kjeldskov J., Paay J.: Public Pervasive Computing Making the Invisible Visible. IEEE Computer, September, 2006.

[9] Bernardos A., Tarrío P., Casar J.: CASanDRA: A Framework to Provide Context Acquisition Services and Reasoning Algorithms for Ambient Intelligence Applications. IEEE Computer, 2009.

[10] Kostakos V., O’Neill E.: Designing Urban Pervasive Systems. IEEE Computer, September 2006.

[11] Suchman L.: Plans and Situated Actions: The Problem of Human-Machine Communication. Cambridge University Press, New York, 1987.

[12] Reilly D., Inkpen K., Watters C.: Controlling, Integrating, and Engaging Context in Urban Computing Research. Proceedings of the 42nd Hawaii International Conference on System Sciences, IEEE. 2009.

[13] Dey A.: Understanding and Using Context. Personal and Ubiquitous Computing, Springer, London, 2001.

[14] Dourish, P.: What we Talk about When we Talk About Context. Journal Personal and Ubiquitous Computing, V. 8, Springer, 2004.

Available: http://dx.doi.org/10.1007/s00779-003-0253-8.

[15] Feng L., Apers P., Jonker W.: Towards Context-Aware Data Management for Ambient Intelligence. Springer, Berlin / Heidelberg, vol. 3180, 2004.

[16] Gu T., Pung H., Zhang D.: Toward an OSGi-Based Infrastructure for ContextAware Applications. IEEE Pervasive Comp., 3(4): 66-74, 2004.

[17] Bardram J.: The Java Context Awareness Framework (JCAF) - A Service Infrastructure and Programming Framework for Context-Aware Applications. Proc. 3rd Int'l. Conf. Pervasive Comp., 2005. 
[18] Behlouli N., Taconet C., Bernard G.: An Architecture for Supporting Development and Execution of Context-Aware Component Applications. Proc. IEEE ICPS'06, 2006.

[19] Oh Y., Han J., Woo W.: A Context Management Architecture for Large-Scale Smart Environments. IEEE Communications Magazine, March 2010.

[20] Zúñiga, C. L., et al.: Design of Service-Oriented Pervasive System for Urban Computing in Cali Zoo (OpenZoo). World Academy of Science, Engineering and Technology, 63: 70-75, 2010.

[21] Kostakos V., et al.: Understanding and Measuring the Urban Pervasive Infrastructure. Personal and Ubiquitous Computing 13(5), Springer, 2009.

[22] Kostakos V. A.: Design Framework for Pervasive Computing Systems. PhD thesis, University of Bath, 2005.

[23] URB@NALAB: Urban Computing Platform to Offer Services Oriented Citizen in Urban Wireless Environments that Contribute a Livinglabs Approach in the Colombian Cities. 2011, co-funded by COLCIENCIAS (Department of Science, Technology and Innovation), http://comba.usc.edu.co/index.php/es/urbnalab/acerca-de-urbanalab.html.

[24] Zúñiga C., Millán A., García A., Solarte Z., Escobar L., Navarro A.: Software Platform for Services in Colombian Cities Using the Living Labs Approach. GLOBECOM Workshops (GC Wkshps), 2011 IEEE, pp. 1258-1262, 5-9 Dec. 2011.

[25] GUACARI LIVING LAB: CO-T1199: Wireless Networks and Digital Inclusion Services in the City of Guacari. Sponsored by the IDB (Interamerican Development Bank) and the Italian Trust Fund of Information and Communication Technology for Development, 2011. http://www . iadb.org/projects/project.cfm?id=CO-T1199\&lang=es.

[26] http://www.valledelcauca.gov.co/publicaciones.php?id=25/. Review in Feb-2014.

\section{Affiliations}

Claudia L. Zuñiga-Cañon

Department of Telematics Engineering, University of Vigo, Vigo, Spain; Research Group COMBA R \& D, Department of Engineering, University of Santiago de Cali, Cali, Colombia, clzuniga@ieee.org, clzuniga@uvigo.es

\section{Juan C. Burguillo}

Department of Telematics Engineering, University of Vigo, Vigo, Spain, J.C.Burguillo@uvigo.es

Received: 15.07 .2013

Revised: 28.11.2013

Accepted: 20.12.2013 